\title{
Customized Microinjection Glass Capillary Needles for P-Element Transformations in Drosophila melanogaster
}

\author{
BioTechniques 33:366-375 (August 2002)
}

\author{
David F.B. Miller, Stacy L. \\ Holtzman, and Thomas C. \\ Kaufman \\ Indiana University, \\ Bloomington, IN, USA
}

\section{INTRODUCTION}

Microinjection techniques are used in vivo with numerous research strategies, such as transposase-mediated germ-line transformation, Gal4-mediated gene regulation, RNA interference, homologous recombination mutagenesis, P-element mutagenesis, antibody inhibition, morpholino antisense oligomers, transient gene expression and regulation, targeted gene regulation with engrailed fusion proteins, drug delivery, and transfer of biologically active cytoplasmic factors (2-16, $18,19,21-34,36,38,39,41-52)$. Many of these techniques were initially characterized in Drosophila melanogaster. However, the wide range of organisms in which others utilize microinjection techniques includes numerous arthropods, vertebrates, stem cells, plants, yeast, paramecium, and cultured cells.

Here we demonstrate a method for generating customized microinjection needles from glass capillary tubes. The technique involves a two-cycle pull in which the capillary tube is stretched during the first cycle and then separates during the second cycle. We utilize a standard Flaming/Brown micropipet puller (model P-87; Sutter Instrument, Novato, CA, USA). Alternative techniques used for the preparation of microinjection needles have been previously described $(1,7,19)$. This analysis describes how to alter the shape of your injection needle in a predictable manner to produce one that is suitable to most techniques and organisms. Previously, we had difficulty producing a needle that had both durability and functionality for injections through the tough chorion of the D. melanogaster embryo during germ-line transformations. The methods described here explain how to alter the parameters of the pipet puller to produce predictable changes in the needle tip shape. We also describe how to calibrate the heat settings, based on the nature of the capillary tube, using the preprogrammed ramp function with some modifications.

The investigation includes Table 1, which summarizes the effects of each first- and second-cycle parameter on the tip shape of the needle. We will also present data that describe the effectiveness of our standard needle for doing Pelement-mediated gene transformation in the D. melanogaster germ-line cells. We examine some limitations of microinjection techniques associated with plasmid sizes, increased viscosity, and needle tolerances.

\section{MATERIALS AND METHODS}

\section{Pulling Injection Needles}

All needles are pulled with a model P-87 Flaming/Brown micropipet puller. The heating element is the box type (cat. no. FB220B; Sutter Instrument). The distance between the bottom of the heating element and the air jet is set at $5 \mathrm{~mm}$. The needles used for this study are borosilicate glass $1 \mathrm{BBL}$ with filament, $1 \mathrm{~mm}$ diameter, $0.058 \mathrm{~mm}$ i.d., and 6 in long (World Precision Instruments, Sarasota, FL, USA). The ramp value (heat units) for the first pull cycle (ramp-1) is determined by the ramp program included in the manufacturer's instructions. The ramp value for the 
Table 1. Summary of Needle Puller Parameters and Effects on Needle Tip Shape

\begin{tabular}{|c|c|c|}
\hline Parameter & Effect on $L$ & Parameter Description \\
\hline & NA & Heat value determined by the glass characteristics. \\
\hline Heat-1 (H1) & & $\begin{array}{l}\text { The } \mathrm{H} 1 \text { setting works best at the ramp-1 value. } \\
\text { Not a good variable for changing L. (Use } 25 \mathrm{U} \\
\text { increments.) }\end{array}$ \\
\hline Heat-2 (H2) & $\sim L$ & $\begin{array}{l}\text { The } \mathrm{H} 2 \text { setting works best at } 25 \mathrm{U} \text { over the } \\
\text { ramp-2 value. (Use } 25 \mathrm{U} \text { increments.) }\end{array}$ \\
\hline Pull-1 (P1) & $\sim(1 / L)$ & $\begin{array}{l}\text { P1 determines pull in cycle } 1 . \\
\text { (Use } 25 \mathrm{U} \text { increments.) }\end{array}$ \\
\hline Pull-2 (P2) & $\sim L$ & $\begin{array}{l}\text { P2 determines pull in cycle } 2 \text {. Not a good variable } \\
\text { for changing } L \text {. (Use } 50 \mathrm{U} \text { increments.) }\end{array}$ \\
\hline Vel-1 (V1) & $\sim(1 / L)$ & $\begin{array}{l}\text { V1 sets the velocity of the separating arms in cycle } \\
\text { 1. (Use } 5 \mathrm{U} \text { increments.) }\end{array}$ \\
\hline Vel-2 (V2) & $\sim(1 / \mathrm{L})$ & $\begin{array}{l}\text { V2 sets the velocity of the separating arms in cycle } \\
\text { 2. (Use } 5 U \text { increments.) }\end{array}$ \\
\hline Time-1 (T1) & $\sim \mathrm{L}$ & f the air pulse in cycle 1. \\
\hline Time-2 (T2) & $\sim L$ & $\begin{array}{l}\text { T2 sets the duration of the air pulse in cycle } 2 . \\
\text { (Use } 50 \mathrm{U} \text { increments.) }\end{array}$ \\
\hline Pressure (Pr) & $\sim(1 / L)$ & $\begin{array}{l}\text { Pr determines the strength of the cooling air pulse. } \\
\text { (Use } 100 \mathrm{U} \text { increments.) }\end{array}$ \\
\hline \multicolumn{3}{|c|}{ 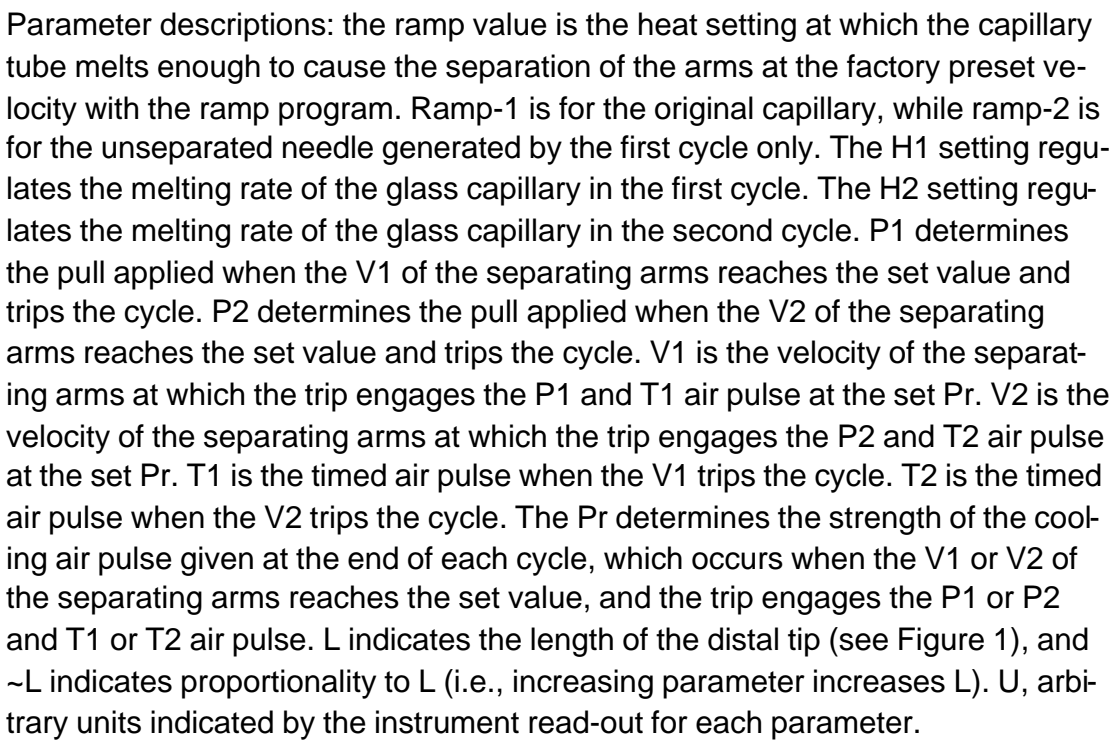 } \\
\hline
\end{tabular}

second pull cycle (ramp-2) is determined by completing the first cycle of a pull program with the user-defined settings (without the complete separation of the capillary tube) and immediately stopping the program with the stop button. The ramp program is now executed with the partially pulled needle (first cycle completed) still in place. All test needles are collected from the right side of the puller to minimize variation.

\section{P-Element Transformations}

P-element transformations are performed using a modified version of the previously reported technique (38, 42). Injections are done into D. melanogaster $\mathrm{w} ; \mathrm{P}[r y+, \Delta 2-3](99 \mathrm{~B}) / \mathrm{TM} 3$ or TM6B syncytial embryos less than $2 \mathrm{~h}$ old. This fly line provides the stable source of transposase required for the mobilization and germ-line transforma- tion of P-element DNA (35). All plasmid DNAs used for injections are prepared with plasmid DNA purification kits (Plasmid Midi Kit; Qiagen, Valencia, CA, USA). The DNA is then precipitated with one-half volume $7 \mathrm{M}$ am monium acetate, $\mathrm{pH} 7.0$, and 3 volumes of ethanol, washed with $70 \%$ ethanol, and dried completely. The DNA is suspended at $1 \mathrm{mg} / \mathrm{mL}$ injection buffer $(0.1$ $\mathrm{M}$ sodium phosphate and $5 \mathrm{mM}$ potassium chloride, $\mathrm{pH} 6.8$, filter-sterilized). All DNA samples are centrifuged at $14000 \times g$ for $10 \mathrm{~min}$ and transferred to a sterile tube before being loaded into the injection needle. Injection needles are pulled according to the description for the standard injection needle (Figure 1) and back-loaded with an Eppen$\operatorname{dorf}^{\circledR}$ microloader tip (Brinkmann Instruments, Westbury, NY, USA) or hand-pulled glass capillary. The injection needles are usually ready for injection after loading. Injections are typically done with 30 psi nitrogen pressure and 5 psi balance pressure to prevent back flow. Occasionally, needles must be carefully sharpened on the frosted side of a microscope slide under halocarbon oil (HC-400; Halocarbon Products, North Augusta, SC, USA) with nitrogen pressure at 80 psi. Sharpening increases sample flow when necessary and can also be used to remove clogs caused by cytoplasm from the egg. Sharpening correctly produces no visible change in the appearance of the needle tip, except that the DNA solution flows at a reasonable rate. Embryos are collected at 1-h intervals on yeast paste and then thoroughly washed in deionized water. Embryos are staged, sorted, and aligned in the same orientation (in pairs) with controlled amounts of deionized water on a microscope coverslip that will fit into a soft agar egg collection plate. The aligned embryos are dried for $5 \mathrm{~min}$ to fix them to the coverslip and covered with a minimal amount of halocarbon oil before injection. Embryos are injected into the posterior end where the germ-line pole cells will form during cellularization. The injections are performed on a Diaphot-TMD inverted microscope (Nikon, Melville, NY, USA) equipped with an MN-188 3-D micromanipulator with NS-188 adaptor, an MO-188 joystick hydraulic micromanipulator, an 
IM 300 microinjector (all Narishige; Fryer Company, Warrensville Heights, $\mathrm{OH}, \mathrm{USA}$ ), and an Eppendorf capillary needle holder. To prevent anoxia, the embryos and coverslips are cleared of halocarbon oil and drained as much as possible without perturbation. The coverslip, with injected embryos, is transferred to a soft egg collection plate, where they are allowed to hatch without being disturbed. Hatched larvae are then transferred to a freshly yeasted vial after two days. Survival frequency is determined by monitoring the number of adult survivors following the injection of the P-element DNA. Constructs used for the injections contain cDNAs for the centrosomin (cnn) gene (20) that are inserted into the Gal4 responder Pelement vector pUAST (5). P-element transformation into germ-line cells is monitored by the rescue of the $w^{1118}$ eye phenotype in the F1 generation by the encoded mini-white gene present in the pUAST vector.

\section{RESULTS}

Figure 1A shows the standard needle used for injections into $D$. melanogaster $\quad \mathrm{w} ; \mathrm{P}[r y+, \Delta 2-3](99 \mathrm{~B})$ embryos. The machine settings used to generate this needle are tabulated in Figure 1B. This needle is durable and penetrates easily through the chorion of the embryo. A two-cycle pull is used to generate this type of needle when all attempts fail in a single cycle, even when several other heating elements and capillary tubes are used. Typically, this needle is formed with an open tip that will accommodate DNA concentrations of $1-2 \mathrm{mg} / \mathrm{mL}$ for P-element transformation. However, it is sometimes necessary to sharpen the tip slightly (see Materials and Methods). The thinly tapered tip is long enough to penetrate well into the posterior of the embryo but sturdy enough to withstand the stress required to penetrate the tough chorion surrounding the entire embryo. Failure to wash off residual yeast results in damage to the needle tip.

We monitor the viability, fertility, and transformation efficiency of the flies following injections to assess the effectiveness of our standard injection needle. The viability of the injected embryos is determined by counting the adults of the injected generation. Viability is $10 \%$ after injections $(n=$ 6738). Fertility is also affected by the injection procedure because we obtain only $68 \%$ fertility of the viable adults in this generation. The transformation efficiency of the total embryos injected is $1.7 \%$, as determined by the rescue of the white $w^{1118}$ eye phenotype. This actually represents $17 \%$ of the viable adults or $25 \%$ of the fertile adults. These results are similar to those previously reported $(35,38)$. We find that, by using higher (visible) injection volumes, we can maintain transformation efficiencies of the fertile adults near $25 \%$ to minimize the labor. This is im portant because the bulk of the effort in generating stable transformants, following clone construction, involves the screening for $w^{1118}$ mutant rescue. Cellularized embryos (incapable of being transformed) are terminated by over-injection to minimize screening efforts. The injection time and pressure required to obtain a visible injection volume are dependent on minor variations with the needle and the viscosity of the DNA solution and therefore must be adjusted by changing the pressure and/or holding time of the injection button. The construct that we use for the control contains a cDNA clone for cnn that is $4 \mathrm{~kb}$. The total size of this mobile DNA fragment (to be incorporated into the genome) is $10 \mathrm{~kb}$, including the mini-white gene with a total plasmid size of $12 \mathrm{~kb}$. We find significantly lower transformation efficien- cies for constructs of larger sizes. Our efforts to transform an $S c r$ regulatory element reporter, with a mobile genom ic element of $30 \mathrm{~kb}$ (32 kb total plasmid size), gives reduced transformation efficiencies of nearly 10 -fold.

Needle puller parameters are adjusted one at a time to establish how they affect the shape of the injection needle tip. We will use the term proportional $(\sim)$ to describe the general relationship of the parameter change to the change in length (L) of the distal taper of the needle tip (Table 1 and Figure 1A). In other words, if the increasing parameter $\mathrm{X}$ increases $\mathrm{L}$, then $\mathrm{X}$ is proportional to $\mathrm{L}(\mathrm{X} \sim \mathrm{L})$. Figure 1 shows the shape and parameters we use for our standard injection needle. This needle is shown in panel A of all figures for comparison. Figure 2 demonstrates the effects of changing the heat, pull, velocity, and time parameters. Increasing cycle 1 heat $(\mathrm{H} 1)$ by $25 \mathrm{U}$ generates a blunter needle tip (Figure 2B), while decreasing $\mathrm{H} 1$ by $25 \mathrm{U}$ has a subtle reverse effect (Figure 2C). Therefore, H1 is inversely proportional to the length (L) of the distal taper $(\mathrm{H} 1 \sim 1 / \mathrm{L})$. However, the $\mathrm{H} 1$ parameter is not a good choice for altering L. Changing cycle 2 heat (H2) has the reverse effect on L. Figure 2D shows a needle generated by increasing $\mathrm{H} 2$ by $25 \mathrm{U}$, which exhibits an increase in $\mathrm{L}$. The needle in Figure 2E is generated by reducing $\mathrm{H} 2$ by $25 \mathrm{U}$ and has a reduced L. Consequently, $\mathrm{H} 2$ is proportional to $\mathrm{L}(\mathrm{H} 2 \sim \mathrm{L})$. Figure $2 \mathrm{~F}$ shows the result of increasing $\mathrm{P} 1$ by $25 \mathrm{U}$, where we find that $\mathrm{L}$ is reduced. Figure

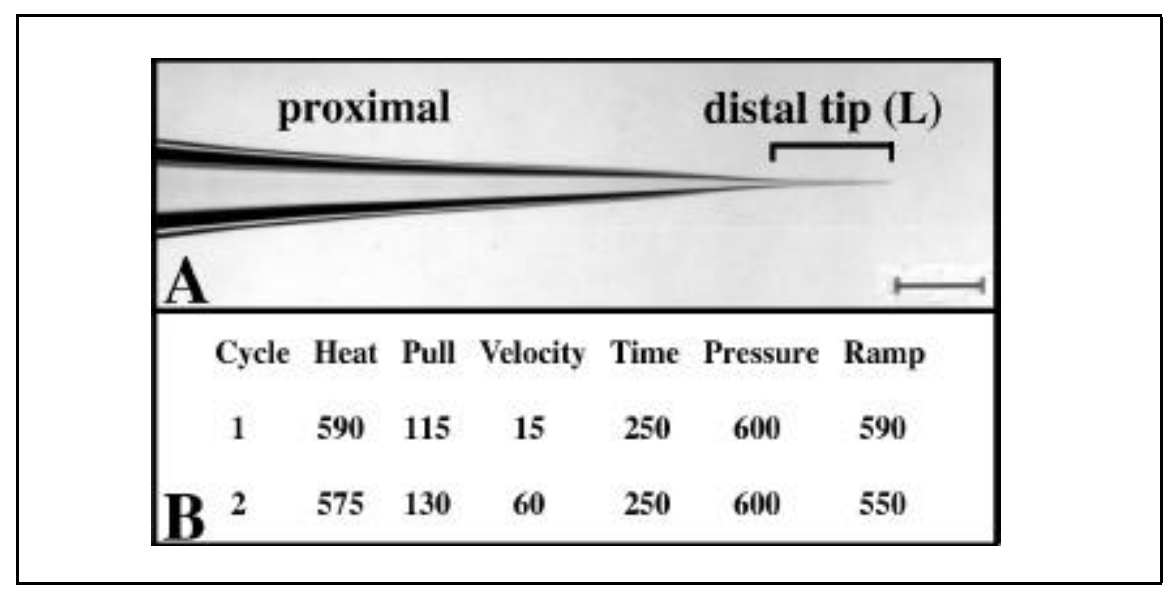

Figure 1. Standard needle shape and parameters for D. melanogaster injections. (A) Standard needle (shown in panel A for all figures). (B) Parameters used to generate the standard needle. Scale bar = $150 \mu \mathrm{m}$. 
$2 \mathrm{G}$ shows a decrease in $\mathrm{P} 1$ by $25 \mathrm{U}$ and an increase in L. Thus, P1 is inversely proportional to $\mathrm{L}(\mathrm{P} 1 \sim 1 / \mathrm{L})$. Changes in $\mathrm{P} 2$ by $50 \mathrm{U}$ show only subtle effects on $\mathrm{L}$ but suggest that $\mathrm{P} 2$ is directly proportional to L (Figure 2, H and I). However, the P2 parameter is not a good choice for altering L. Figure 2J shows the standard again for comparison. Increasing V1 by $5 \mathrm{U}$ decreases L significantly (Figure 2K), while decreasing $\mathrm{V} 1$ by $5 \mathrm{U}$ increases L (Figure 2L). Therefore, V1 units are inversely proportional to $\mathrm{L}(\mathrm{V} 1 \sim 1 / \mathrm{L})$. Changes in $\mathrm{V} 2$ by $5 \mathrm{U}$ show similar affects on $\mathrm{L}$ (i.e., V2 1/L). However, the proximal taper of the needle (away from the tip) is oppositely affected (Figure 2, M and $\mathrm{N})$. Changing the time parameters (T1 and T2; cycles 1 and 2, respectively) also alter needle morphology. The time setting for the standard (Figure 1 and Figure 2, A and J) is set at $250 \mathrm{U}$. This is the maximum setting for this parameter. Figure $2 \mathrm{O}$ shows a needle that is generated by decreasing T1 by $50 \mathrm{U}$. The needle in Figure $2 \mathrm{P}$ is generated by reducing T1 by $100 \mathrm{U}$. Clearly, T1 units are directly proportional L (T1 L), as we observe decreases in L. The needles in Figure 2, Q and R, are generated by reducing the $\mathrm{T} 2$ parameter by 50 and

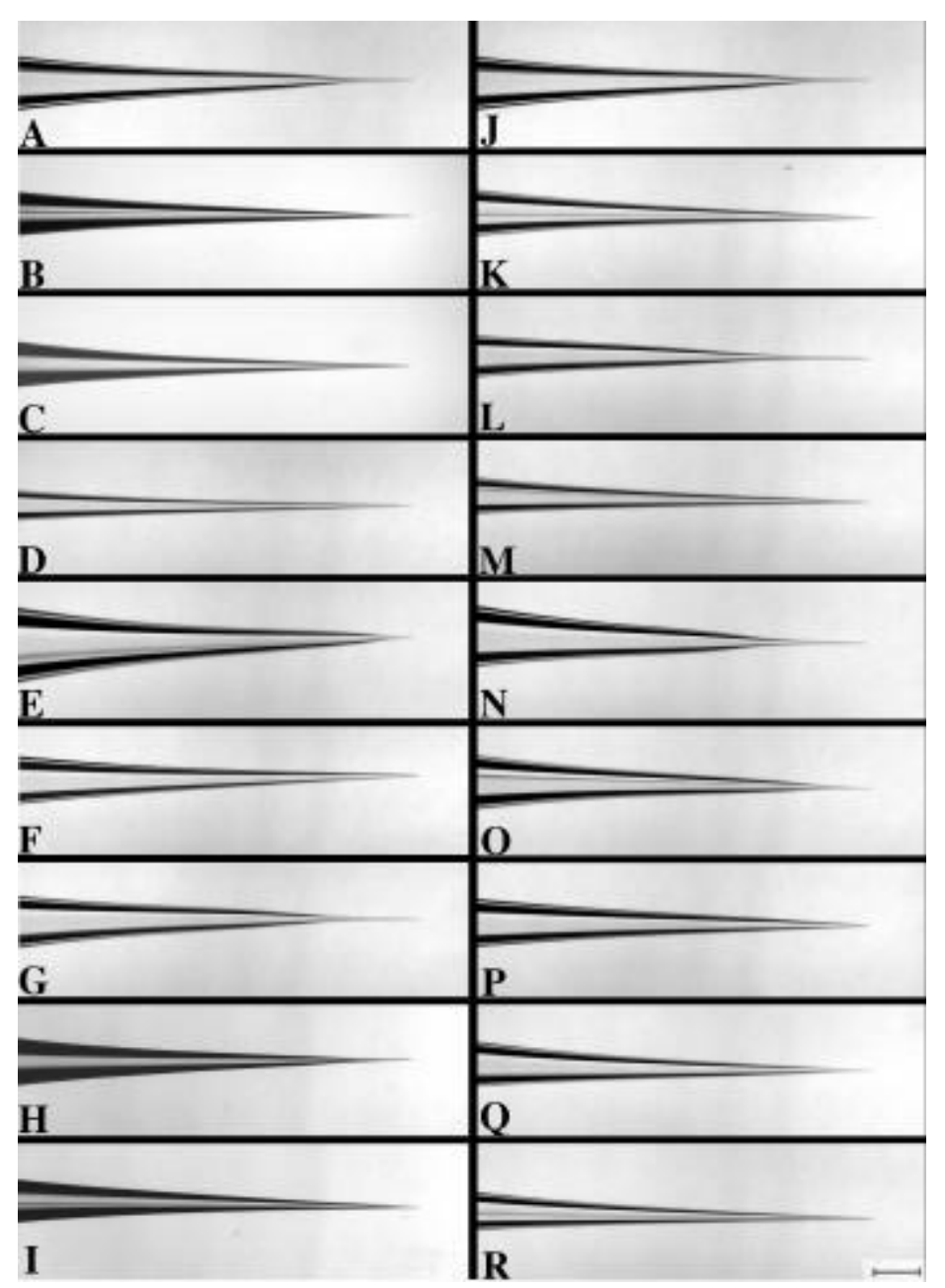

Figure 2. Effects on needle shape by altering parameters. (A) Standard needle (settings in Figure 1). (B) Increase H1 by $25 \mathrm{U}$ from standard. (C) Decrease H1 by $25 \mathrm{U}$. (D) Increase H2 by $25 \mathrm{U}$. (E) Decrease $\mathrm{H} 2$ by $25 \mathrm{U}$. (F) Increase P1 by $25 \mathrm{U}$ from standard. (G) Decrease P1 by $25 \mathrm{U}$. (H) Increase P2 by 50 U. (I) Decrease P2 by 50 U. (J) Standard (Figure 1). (K) Increase V1 by 5 U compared to the standard. (L) Decrease V1 by 5 U. (M) Increase V2 by 5 U. (N) Decrease V2 by 5 U. Note that the maximum settings for T1 and T2 are $250 \mathrm{U}$ (standard settings). (O) Decrease T1 by $50 \mathrm{U}$. (P) Decrease T1 by 100 U. (Q) Decrease T2 by 50 U. (R) Decrease T2 by $100 \mathrm{U}$. Scale bar $=150 \mu \mathrm{m}$.

$100 \mathrm{U}$, respectively. Reducing this parameter has a subtle effect of reducing $\mathrm{L}$ and appears to be directly proportional to $\mathrm{L}$ (T2 L). However, reducing T2 seems to alter the proximal taper of the needle more significantly when we detect an increase in this length.

Figure 3 shows that cooling air pressure (Pr) also affects the shape of the injection needle. This parameter cannot be changed independently for each cycle. The maximal Pr setting is 600, which is the setting used for the standard (Figures 1 and 3A). Reducing the Pr setting by $100 \mathrm{U}$ (Figure 3B) and 200 U (Figure 3C) produces needles with an increased L. Reducing the Pr setting by $300 \mathrm{U}$ causes the capillary to separate during the first cycle (data not shown). Therefore, P1 was reduced by $50 \mathrm{U}$, and P2 was reduced by $90 \mathrm{U}$ when $\operatorname{Pr}$ was reduced by $300 \mathrm{U}$. This allows a two-cycle pull for the lower $\operatorname{Pr}$ setting (Figure 3D). Reducing Pr by

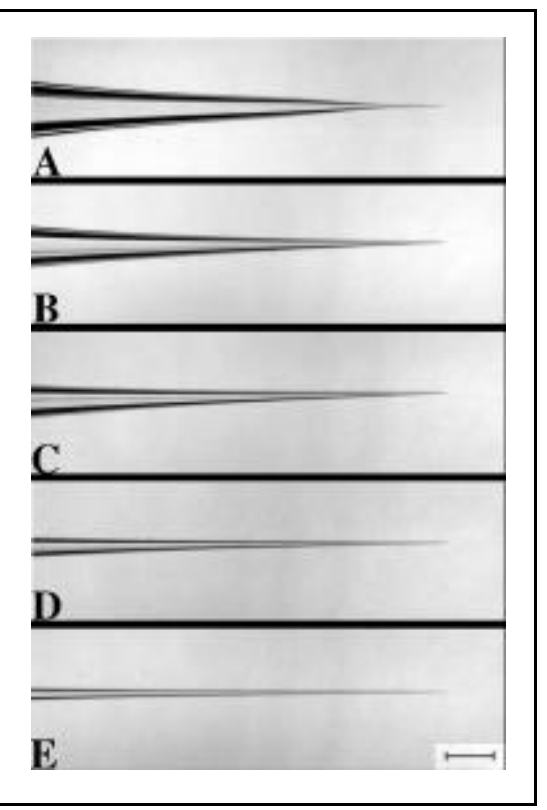

Figure 3. Effects on needle shape by altering cooling air pressure (Pr). (A) Standard needle (settings in Figure 1). (B) Decreased Pr by $100 \mathrm{U}$ compared to standard. (C) Pr was decreased $200 \mathrm{U}$ below the standard. (D) Pr was decreased $300 \mathrm{U}$ (along with adjusted pull settings below). It should be emphasized that the capillary becomes separated during the first cycle, when $P r$ is reduced by $300 \mathrm{U}$. Consequently, the pull settings in both the first and second cycles adjusted to demonstrate alternative settings necessary for shifting the range of allowable Pr settings for two-cycle pulls. P1 was reduced by $50 \mathrm{U}$, and $\mathrm{P} 2$ was reduced by 90 U. (E) Pr was decreased $400 \mathrm{U}$ (with adjusted pull settings in Figure 3D). Scale bar $=150 \mu \mathrm{m}$. 


\section{Research Report}

$400 \mathrm{U}$, compared to the standard (along with the new P1 and P2 settings; Figure 3D), increases L even more drastically (Figure 3E). These data indicate that $\mathrm{Pr}$ is inversely proportional to $\mathrm{L}(\operatorname{Pr} \sim 1 / \mathrm{L})$ and the proximal taper of the needle.

\section{DISCUSSION}

The increasing number of biological techniques that require microinjection prompted us to investigate new methods for generating customized needles. Additionally, these techniques are being applied to a wide range of organisms that include representatives from several animal and plant groups. We have developed a two-cycle pull protocol that allows more control over the shape of the injection needle. Our attempts to generate a durable tip shape with one-cycle pulls were unsuccessful with a wide range of heating elements and capillaries. However, by using a two-cycle pull, we pre-stretched the capillary tube in the first cycle to allow more control over the tip shape in the second cycle. The box-heating filament produced a more uniform needle shape with a wider range of control. Using the preprogrammed ramp function of the Flaming/Brown micropipet needle puller in a unique manner (see Materials and Methods), we determined the proper heat parameter values for the capillary tube being used. The ramp value is a heat setting that generates the necessary amount of capillary meltdown to cause the puller arms to separate at the preset factory velocity. Typically, the first-cycle heat value was set at ramp-1. The second-cycle heat value usually worked best $25 \mathrm{U}$ above the ramp-2 value. We first established settings for the needle puller that generated the standard needle for P-element germ-line transformations in D. mela- nogaster embryos (Figure 1). We then altered each parameter of the needle puller, one at a time, and compared the needle product with our standard to determine the effect on needle tip shape. Table 1 summarizes all the effects of all independent parameter changes on $\mathrm{L}$.

Most first-cycle parameters (e.g., pressure) used to generate new needle shapes have a limited range of values. Otherwise, the capillary tube will be separated in the first cycle, resulting in an unsatisfactory needle. Preventing separation in the first cycle can usually be accomplished by readjusting other parameters, as demonstrated in Figure 3. This was true for each of the parameters in which we saw a limited range of useable values, contingent on all other settings. This was determined empirically each time. Another limitation was the capillary tube. It could not be too thick or the ramp test would melt the heating filament. We were able to pull 
useful needles with three-cycle pulls; however, there appeared to be no advantage to this approach for the capillary tubes we used. Three-cycle pulls may be useful for thicker capillary tubes to pre-stretch them enough before the final separating pull. The $5-\mathrm{mm}$ distance between the heating element and the air jet is often reduced to $3 \mathrm{~mm}$ (personal communication, Adair Oesterle, Sutter Instruments) and may be responsible for the high-pressure settings $(\mathrm{Pr}=600)$ necessary to obtain a functional tip in our assay (Figure 1).

The standard needle (Figure 1) was developed for P-element DNA injections through the tough chorion enclosing D. melanogaster embryos. This technique required a needle with a fine tip to minimize trauma to the animal. The thin distal portion of the tip also needed to be relatively short to avoid flexing during penetration, yet long enough to avoid penetration of the embryo with the wider proximal region. For example, the proximal portion of the tip could not be too thin or the needle would flex when trying to penetrate the embryonic chorion (Figure 2, D, M, and R, and Figure 3, C-E). Alternatively, needles with shorter distal tip tapers (L) create a larger opening and reduce viability due to cytoplasmic leakage (Figure 2, B, E, F, K, and P). We have successfully utilized the standard needle for injections of dsRNA in vivo (RNA interference), rhodamine-tagged tubulin and actin, colchicine, and cytocalasin B into D. melanogaster embryos (unpublished data). We found that our two-cycle needles were useful for RNA-interference injections into other insects as well (21). These injection needles are versatile tools for studying the evolution of developmental processes across broad phylogenetic groups of organisms. Understanding the effect of each parameter on needle shape permitted the development of customized needles with the desired characteristics dictated by the material being injected and the organism/tissue. Other studies have described additional techniques for analyzing needle characteristics, such as inner diameter (40). Our injection tests demonstrated typical survival and transformation frequencies $(35,38)$. However, these results were somewhat variable and depended on the expertise of the user as well as the nature of the DNA being injected. The construct design of the 4-kb cnn cDNA in the pUAST vector should not have affected the data because transcriptional activation (expression of the cnn transgene) requires Gal4 co-expression. Similarly, the 32-kb Scr regulatory construct only expresses Gal4, which has no effect on viability. Some Hox (e.g., Scr) regulatory regions repress mini-white expression and may have reduced our transformation efficiencies for this larger construct (17, 37), although this repressive effect seems to exhibit only patchy mini-white repression in the eye when heterozygous. Presumably, the limitations associated with the larger construct were higher sample viscosity, lower molar concentrations of the DNA, and reduced genomic insertion rates. In summary, the standard needle was found to be useful for injecting plasmid DNA sizes ranging from 12 to $32 \mathrm{~kb}$. We also found this needle useful for DNA concentrations as high as $2 \mathrm{mg} / \mathrm{mL}$. Given the relatively large sizes of these plasmids, this needle should be useful for most microinjection techniques.

\section{ACKNOWLEDGMENTS}

Thanks to doctorandus Robert "Tank" Eisman for reviewing the manuscript. We also thank Cythia Hughes, Paul Liu, and Tim Megraw for testing many of our experimental needles. Many thanks to Dee Verostko and Ruth Binkley for helping to maintain a smoothly run laboratory and a pleasant work environment. We would also like to thank Adair Oesterle at Sutter Instruments for recommending that we report the distance between the air jet and the heating element. T.C.K. is an investigator for the Howard Hughes Medical Institute.

\section{REFERENCES}

1.Alekseev, A.N. and S.P. Chunikhin. 1987. A method of preparing glass microneedles for injecting ticks and other small arthropods. Med. Parazitol. (Mosk) 6:69-70.

2.Banga, S.S. and J.B. Boyd. 1992. Oligonucleotide-directed site-specific mutagenesis in Drosophila melanogaster. Proc. Natl. Acad. Sci. USA 89:1735-1739.

3.Bibikova, M., D. Carroll, D.J. Segal, J.K.
Trautman, J. Smith, Y.G. Kim, and S. Chandrasegaran. 2001. Stimulation of homologous recombination through targeted cleavage by chimeric nucleases. Mol. Cell. Biol. 21:289-297.

4.Bier, E., H. Vaessin, S. Shepherd, K. Lee, K. McCall, S. Barbel, L. Ackerman, R. Carretto, et al. 1989. Searching for pattern and mutation in the Drosophila genome with a PlacZ vector. Genes Dev. 3:1273-1287.

5.Brand, A.H. and N. Perrimon. 1993. Targeted gene expression as a means of altering cell fates and generating dominant phenotypes. Development 118:401-415.

6.Bravo, R. and J.E. Celis. 1980. Direct microinjection of rabbit globin mRNA into mouse 3T3 cells. Analysis of the polypeptides synthesized in vivo. Exp. Cell Res. 126:481485.

7.Brazzle, J., I. Papautsky, and A.B. Frazier. 1999. Micromachined needle arrays for drug delivery or fluid extraction. IEEE Eng. Med. Biol. Mag. 18:53-58.

8.Capecchi, M.R. 1980. High efficiency transformation by direct microinjection of DNA into cultured mammalian cells. Cell 22:479488.

9.Casey, B.P. and P.M. Glazer. 2001. Gene targeting via triple-helix formation. Prog. Nucleic Acid Res. Mol. Biol. 67:163-192.

10.Celis, J.E. 1984. Microinjection of somatic cells with micropipettes: comparison with other transfer techniques. Biochem. J. 223:281291.

11.Davis, B.R., J. Yannariello-Brown, N.L. Prokopishyn, Z. Luo, M.R. Smith, J. Wang, N.D. Carsrud, and D.B. Brown. 2000. Glass needle-mediated microinjection of macromolecules and transgenes into primary human blood stem/progenitor cells. Blood. 95:437444.

12.Eggleston, P. and Y. Zhao. 2001. Gene targeting in mosquito cells: a demonstration of "knockout" technology in extrachromosomal gene arrays. BMC Genet. 2:11.

13.Elliott, B. and M. Jasin. 2001. Repair of double-strand breaks by homologous recombination in mismatch repair-defective mammalian cells. Mol. Cell. Biol. 21:2671-2682.

14.Fire, A., S. Xu, M.K. Montgomery, S.A. Kostas, S.E. Driver, and C.C. Mello. 1998. Potent and specific genetic interference by double-stranded RNA in Caenorhabditis elegans. Nature 391:806-811.

15.Folger, K.R., E.A. Wong, G. Wahl, and M.R. Capecchi. 1982. Patterns of integration of DNA microinjected into cultured mam malian cells: evidence for homologous recom bination between injected plasmid DNA molecules. Mol. Cell. Biol. 2:1372-1387.

16.Gibbs, P.D., A. Gray, and G. Thorgaard. 1994. Inheritance of $P$ element and reporter gene sequences in zebrafish. Mol. Mar. Biol. Biotechnol. 3:317-326.

17.Gindhart, Jr., J.G. and T.C. Kaufman. 1995. Identification of Polycomb and trithorax group responsive elements in the regulatory region of the Drosophila homeotic gene sex combs reduced. Genetics 139:797-814.

18.Golic, M.M., Y.S. Rong, R.B. Petersen, S.L. Lindquist, and K.G. Golic. 1997. FLP-mediated DNA mobilization to specific target sites 
in Drosophila chromosomes. Nucleic Acids Res. 25:3665-3671.

19.Henry, S., D.V. McAllister, M.G. Allen, and M.R. Prausnitz. 1998. Microfabricated microneedles: a novel approach to transdermal drug delivery. J. Pharm. Sci. 87:922-925.

20.Heuer, J.G., K. Li, and T.C. Kaufman. 1995. The Drosophila homeotic target gene centrosomin (cnn) encodes a novel centrosomal protein with leucine zippers and maps to a genomic region required for midgut morphogenesis. Development 121:3861-3876.

21.Hughes, C.L. and T.C. Kaufman. 2000. RNAi analysis of deformed, proboscipedia, and sex combs reduced in the milkweed bug Oncopeltus fasciatus: novel roles for Hox genes in the hemipteran head. Development 127:3683-3694.

22.Igoucheva, O., V. Alexeev, and K. Yoon. 2001. Targeted gene correction by small single-stranded oligonucleotides in mammalian cells. Gene Ther. 8:391-399.

23.Joris, H., Z. Nagy, H. Van de Velde, A. De Vos, and A. Van Steirteghem. 1998. Intracytoplasmic sperm injection: laboratory set-up and injection procedure. Hum. Reprod. Suppl. 1 13:76-86.

24.Kennerdell, J.R. and R.W. Carthew. 1998. Use of dsRNA-mediated genetic interference to demonstrate that frizzled and frizzled 2 act in the wingless pathway. Cell 95:1017-1026.

25.Kessler, D.S. 1997. Siamois is required for formation of Spemann's organizer. Proc. Natl. Acad. Sci. USA 94:13017-13022.

26.Khillan, J.S., P.A. Overbeek, and H. Westphal. 1985. Drosophila $\mathrm{P}$ element integration in the mouse. Dev. Biol. 109:247-250.

27.Kirschner, M. and E. Schulze. 1986. Morphogenesis and the control of microtubule dynamics in cells. J. Cell Sci. Suppl. 5:293-310.

28. Koizumi, S. 1974. Microinjection and transfer of cytoplasm in paramecium. Experiments on the transfer of $\kappa$ particles into cells at different stages. Exp. Cell Res. 88:74-78.

29.Lange, A.B., K.K. Chyong, and M.I. Sokolova. 1981. Intraovarian oil injection method and its use in determining the physiological age of female blood-sucking mosquitoes (Diptera, Culicidae). Med. Parazitol. (Mosk) 50:51-53.

30.Miller, L.H., R.K. Sakai, P. Romans, R.W. Gwadz, P. Kantoff, and H.G. Coon. 1987. Stable integration and expression of a bacterial gene in the mosquito Anopheles gambiae. Science 237:779-781.

31.Mitchison, T., L. Evans, E. Schulze, and M. Kirschner. 1986. Sites of microtubule assem bly and disassembly in the mitotic spindle. Cell 45:515-527.

32.O'Brochta, D.A., S.P. Gomez, and A.M. Handler. 1991. P element excision in Drosophila melanogaster and related drosophilids. Mol. Gen. Genet. 225:387-394.

33.Proctor, G.N. 1992. Microinjection of DNA into mammalian cells in culture: theory and practice. Methods Mol. Cell. Biol. 3:209-231.

34.Rio, D.C. and G.M. Rubin. 1985. Transformation of cultured Drosophila melanogaster cells with a dominant selectable marker. Mol. Cell. Biol. 5:1833-1838.

35.Robertson, H.M., C.R. Preston, R.W. Phillis, D.M. Johnson-Schlitz, W.K. Benz, and W.R. Engels. 1988. A stable genomic source of P element transposase in Drosophila melanogaster. Genetics 118:461-470.

36.Rong, Y.S. and K.G. Golic. 2001. A targeted gene knockout in Drosophila. Genetics 157:1307-1312.

37.Roseman, R.R., K. Morgan, D.R. Mallin, R. Roberson, T.J. Parnell, D.J. Bornemann, J.A. Simon, and P.K. Geyer. 2001. Longrange repression by multiple polycomb group $(\mathrm{PcG})$ proteins targeted by fusion to a defined DNA-binding domain in Drosophila. Genetics 158:291-307.

38. Rubin, G.M. and A.C. Spradling. 1982. Genetic transformation of Drosophila with transposable element vectors. Science 218:348353.

39.Schnorf, M., G. Neuhaus-Url, A. Galli, S. Iida, I. Potrykus, and G. Neuhaus. 1991. An improved approach for transformation of plant cells by microinjection: molecular and genetic analysis. Transgenic Res. 1:23-30.

40.Schnorf, M., I. Potrykus, and G. Neuhaus. 1994. Microinjection technique: routine system for characterization of microcapillaries by bubble pressure measurement. Exp. Cell Res. 210:260-267.

41.Sonoda, E., C. Morrison, Y.M. Yamashita, M. Takata, and S. Takeda. 2001. Reverse genetic studies of homologous DNA recombination using the chicken B-lymphocyte line, DT40. Philos. Trans. R. Soc. Lond. B. Biol. Sci. 356:111-117.

42.Spradling, A.C. and G.M. Rubin. 1982. Transposition of cloned $\mathrm{P}$ elements into Drosophila germ line chromosomes. Science. 218:341-347

43.Stith, B.J. and W.R. Proctor. 1989. Microinjection of inositol 1,2-(cyclic)-4,5-trisphosphate, inositol 1,3,4,5-tetrakisphosphate, and inositol 1,4,5-trisphosphate into intact Xenopus oocytes can induce membrane currents independent of extracellular calcium. J. Cell. Biochem. 40:321-330.

44.Summerton, J. and D. Weller. 1997. Morpholino antisense oligomers: design, preparation, and properties. Antisense Nucleic Acid Drug Dev. 7:187-195.

45.Sved, J.A., W.B. Eggleston, and W.R. Engels. 1990. Germ-line and somatic recombination induced by in vitro modified $\mathrm{P}$ elements in Drosophila melanogaster. Genetics. 124:331-337

46.Tabara, H., A. Grishok, and C.C. Mello. 1998. RNAi in C. elegans: soaking in the genome sequence. Science 282:430-431.

47.Takata, M., M.S. Sasaki, S. Tachiiri, T. Fukushima, E. Sonoda, D. Schild, L.H. Thompson, and S. Takeda. 2001. Chromosome instability and defective recombinational repair in knockout mutants of the five Rad51 paralogs. Mol. Cell. Biol. 21:28582866.

48. Vilen, H., S. Eerikainen, J. Tornberg, M.S. Airaksinen, and H. Savilahti. 2001. Construction of gene-targeting vectors: a rapid $\mathrm{Mu}$ in vitro DNA transposition-based strategy generating null, potentially hypomorphic, and conditional alleles. Transgenic Res. 10:69-80.

49. Warn, R.M., L. Flegg, and A. Warn. 1987. An investigation of microtubule organization and functions in living Drosophila embryos by injection of a fluorescently labeled antibody against tyrosinated $\alpha$-tubulin. J. Cell Biol. 105:1721-1730.

50.Wilson, C.J., C. Guglielmo, N.D. Moua, M. Tudor, G. Grosveld, R.A. Young, and P.J. Murray. 2001. Yeast artificial chromosome targeting technology: an approach for the deletion of genes in the $\mathrm{c} 57 \mathrm{bl} / 6$ mouse. Anal. Biochem. 296:270-278.

51.Xiaohui Wang, H., J.F. Viret, A. Eldridge, R. Perera, E.R. Signer, and M. Chiurazzi. 2001. Positive-negative selection for homologous recombination in Arabidopsis. Gene 272:249-255.

52.Zhao, R., S.A. Fahs, H. Weiler, and S.A. Duncan. 2001. An efficient method to successively introduce transgenes into a given genomic locus in the mouse. BMC Dev. Biol. 1:10.

Received 5 November 2001; accepted 3 April 2002.

Address correspondence to:

Dr. Thomas C. Kaufman

Department of Biology

Howard Hughes Medical Institute

Indiana University

Bloomington, IN 47405, USA

e-mail: kaufman@bio.indiana.edu 